\title{
Sialyl Tn Antigen
}

National Cancer Institute

\section{Source}

National Cancer Institute. Sialyl Tn Antigen. NCI Thesaurus. Code C1226.

A tumor-associated core-region carbohydrate antigen of epithelial mucin, expressed in most colon carcinoma, mucinous carcinoma, pancreatic cancer, gastric, lung, breast, and ovarian carcinoma. Sialosyl-Tn (ST n) antigen has been shown to be highly sensitive and a specific marker of colorectal cancer, associated with more aggressive diseases and poor prognosis. ST $n$ antigen and its immediate precursor, T $n$ antigen, are mucin type glycoprotein structures associated with the earliest steps of mucin O-linked glycosylation. When combined with a carrier molecule, keyhole limpet hemocyanin (KLH), this antigen may be co-administered with oral cyclophosphamide as an immune modulator. 